\title{
As Garantias Constitucionais do Processo nas Ações Coletivas
}

\author{
Ada Pellegrini Grinover
}

Prof. Titular da Universidade de São Paulo

\begin{abstract}
RESUMO: I - INTRODUÇÃO: 1 As fases do direito processual: do sincretismo ao instrumentalismo; 2 - Processo constitucional e instrumentalismo substancial: continuidade; 3 - $\mathrm{O}$ eventual conflito entre as garantias do "devido processo legal" e um processo aderente à realidade sócio-jurídicą; 4 - A transformação das garantias constitucionais: do individual ao social; 5 - Os conflitos emergentes: da civilização individualista à sociedade de massa; II - OS INTERESSES DIFUSOS NO QUADRO DAS GARANTIAS CONSTITUCIONAIS DO PROCESSO: 6 - Interesses coletivos e interesses difusos propriamente ditos: distinção; 7 - O objeto dos interesses difusos: bens indivisíveis ou divisíveis; 8 - Questōes constitucionais: coisa julgada, contraditória e direito de defesa; 9 - O regime da coisa julgada nas ações coletivas: o tratamento nos interesses coletivos e nos difusos; 10 - Segue: ação meramente declaratória, constituiiva e condenatória; condenação à obrigação de fazer ou não fazer; condenação à indenização pelo dano indivisível. A solução brasileira; 11 - Segue: condenação à indenização pelos danos pessoalmente sofridos: o julgado "secundum eventum litis"; 12 - Correlação entre coisa julgada e legitimação para agir nas ações coletivas. Os esquemas da legitimação. A "representatividade adequada"; 13 - O fundamento constitucional da "representatividade adequada"; 14 - Compatibilidade entre o "devido processo legal" e as técnicas das ações coletivas para a tutela dos interesses difusos; 15 - Conclusão.
\end{abstract}

\section{I - INTRODUÇÃO}

1 - Uma análise do direito processual que leve em conta suas tendências apontará claramente a existência de diversas fases, de características diversas. Até Bülow, a fase "sincretista" (1) havia considerado o processo umbilicalmente

* Aula inaugural proferida na Faculdade de Direito da Universidade de São Paulo na sessão solene de abertura dos Cursos Jurídicos do ano letivo de 1987. Foram acrescentadas as notas.

(1) O termo é utilizado, no Brasil, por Cândido Dinamarco, "A instrumentalidade do processo", tese para concurso de cátedra, São Paulo, Edit. Revista dos Tribunais, 1986. 
ligado ao direito civil, de modo que era natural que o primeiro esforço no sentido da construção da ciência processual fosse em direção à sua autonomia. E assim, por mais de um século, os processualistas preocuparam-se substancialmente com a afirmação e a comprovação dessa autonomia, numa fase técnicocientífica de caráter essencialmente conceitual, em que se construíram categorias dogmáticas, dentro de sistemas de rigorosa coerência interna ${ }^{(2)}$.

O esforço era necessário e seus frutos científicos permanecem até hoje, como conquistas definitivamente adquiridas pelo direito processual. Mas a seu extraordinário progresso científico não correspondera o melhor funcionamento da justiça. Muito ao contrário. Iniciou-se assim, nestas últimas décadas, a fase do denominado "instrumentalismo" do processo ${ }^{(3)}$, em que a instrumentalidade, antes afirmada apenas de modo nominal e formal, dentro do próprio sistema, se transforma em ponto nodal, extravasando para outros enfoques e novas posturas. E todo o sistema processual passa a ser visto como instrumento para atingir os escopos jurídicos, sociais e políticos a que se destina.

Assim vieram, primeiro, os estudos constitucionais do processo, nota característica da disciplina a partir dos ános cincoenta ${ }^{(4)}$, quando os processualistas voltaram suas atenções para o dado jurídico-constitucional, como resultante das forças políticas e sociais da sociedade em determinado momento histórico ${ }^{(5)}$. E o processo deixou de ser visto como instrumento meramente técni-

(2) Barbosa Moreira, Tendências contemporâneas do direito processual civil, in "Temas de Direito Processual", Terceira Série, São Paulo, Saraiva, 1984, p. 2/3 (também publicado em espanhol, na Revista Uruguaya de Derecho Processual, no 3, 1983) recorda as acerbas polêmicas doutrinárias em torno da natureza da ação, da coisa julgada, do objeto do processo.

(3) Barbosa Moreira, op. e loc. cit.; Dinamarco dedicou diversos estudos à função instrumental do sistema processual, culminando recentemente na tese A instrumentalidade cit.

(4) Na Itália, Calamandrei, Liebman, Cappelletti, Denti, Comoglio, Vigoriti, Grevi, Trocker, Chiavario; na Espanha, Alcalá-Zamora; Couture, Vescovi, Gelsi-Bidart no Uruguai; Burgoa, Fix-Zamudio e Ovalle Favela no México; na Argentina, Morello, Berizonce, Hitters; no Brasil, Frederico Marques, Pellegrini Grinover, Calmon de Passos, Galeno Lacerda, Kazuo Watanabe, são apenas alguns dentre os tantos que se dedicaram ao direito processual constitucional, entendido como ccndensação metodológica e sistemática dos princípios constitucionais do processo.

(5) Ver, na Autora, “As garantias constitucionais do direito de ação, São Paulo, Edit. Revista dos Tribunais, 1973, p. 73 e ss. 
co, para transformar-se em instrumento ético e político de atuação da justiça e de garantia da liberdade ${ }^{(6)}$.

Mas ainda não haveria de parar a caminhada de processualista: da perspectiva constitucional, que já havia salientado elementos relativos ao "fato", passou-se à consciência cada vez mais clara da necessidade de o processo ter plena e total aderência à realidade sócio-jurídica a que se destina, cumprindo sua primordial vocação, que é a de servir de instrumento à efetiva realização dos direitos $^{(7)}$. E o eixo dos estudos deslocou-se, desse modo, para o problema da "efetividade"(8), analisada sob os mais diversos aspectos, incluindo o de "acesso à justiça" (9).

Acesso à justiça, este, que já foi visto sob o enfoque de programa de reforma e de método de pensamento ${ }^{(10)}$ e que levou à percuciente análise de diversos problemas: desde a assistência judiciária ${ }^{(11)}$ e a legitimação para agir ${ }^{(12)}$ até a análise dos novos conflitos, próprios de uma sociedade de massa, com a

(6) Assim Cintra, Pellegrini Grinover \& Dinamarco, Teoria geral do Processo, 6a ed., São Paulo, Edit. Revista dos Tribunais, 1986, págs. 46/47.

(7) Assim se exprime Kazuo Watanabe, Contribuição ao estudo da cognição no processo civil, Tese de doutorado, São Paulo, 1985, p. 2.

(8) Ver, no Brasil, Barbosa Moreira, Notas sobre a "efetividade", do processo, in "Estudos de Direito processual" em homenagem a José Frederico Marques, São Paulo, Saraiva, 1982, p. 203 e ss., bem como a tese de Dinamarco, Instrumentalidade cit.

(9) Ver principalmente a monumental obra de Cappelletti e outros, "Access to Justice", Milão, Giuffré, 1978, em 6 volumes, e "Access to Justice and the Welfare State", Alphen an den Rijn, Bruxelas - Stuttgart - Florença, 1981.

(10) Cappelletti, Accesso alla giustizia come programma di riforma e come metodo di pensiero, in Riv. dir. proc., 1982.

(11) Ver, por todos, Denti, "Accessibility of legal procedures for the underpriviliged: legal aid and advice", Relatório Geral para o Congresso Internacional de Direito processual civil, Gand, 1977. No Brasil, sobre as novas dimensões da assistência judiciária, no enfoque do acesso à justiça e à ordem jurídica justa, Pellegrini Grinover, "Assistência Judiciária e acesso à Justiça”, e Watanabe, "Assistência Judiciária como instrumento de acesso à Ordem Jurídica Justa”, in Rev. Proc. Ger. Est. SP., vol. 22, págs. 17 e ss. e 87 e ss.

(12) Dentre tantos, v. Moniz de Aragão, “O Estado de Direito e o direito de ação", in. Rev. dir. proc., v. 16, p. 69 e ss.; Barbosa Moreira, Notas sobre a "efetividade" cit, esp. págs. $208 / 13$. 
efetiva tutela jurisdicional de direitos e interesses emergentes, como os interesses difusos ${ }^{(13)}$ e os próprios da denominada "justiça menor"(14).

2 - O enfoque constitucional do processo constituiu, assim, a primeira etapa no caminho do instrumentalismo substancial ${ }^{(15)}$, culminando nos atuais estudos sócio-jurídicos em torno do problema da adequação do processo à realidade concreta. Se assim é, não deveria haver fraturas, mas sim coincidência e complementariedade entre as duas visões.

Aliás, não há dúvidas que o próprio acesso à justiça configura garantia constitucional, enquadrável no direito de ação e de defesa, pelo qual a todos se assegura igual possibilidade de tutela jurisdicional ${ }^{(16)}$. E, por sua vez, a igual possibilidade de tutela jurisdicional tem exatamente em vista a real viabilização do direito material por intermédio do processo ${ }^{(17)}$, que nada mais é do que sua efetividade.

3 - Ocorre, porém, que a preocupação central dos processualistas que se debruçaram sobre os grandes temas constitucionais realçou, de início, as garantias das partes. E acontece que a visão abstratamente garantidora do processo poderia realmente entrar em choque com a idéia de um processo renovado, que demanda a reformulação dos institutos processuais, a fim de adequá-los a uma diversa realidade sócio-jurídica.

(13) Ver o volume "A tutela dos interesses difusos", organizado pela Autora, São Paulo, Max Limonad, 1985, com a bibliografia geral mencionada a págs. 257/258.

(14) Ver o volume "Juizado especial de pequenas causas", organizado por Watanabe, São Paulo, ed.. Revista dos Tribunais, 1985, incluindo estudos de direito comparado.

(15) A expressão é de Watanabe, Contribuição, cit., p. 2.

(16) É esta a primeira grande preocupação da parte do processo constitucional que denominamos "tutela constitucional do processo" e que pode ser subdividida, para fins didáticos, em "direito à tutela jurisdicional" (ou direito de ação e de defesa) e "devido processo legal”. Cintra, Pellegrini Grinover e Dinamarco, Teoria geral cit., p. 52.

(17) Ver, na Itália, Comoglio, La garanzia costituzionale dell'azione nel processo civile, Pádua, Cedam, 1970, principalmente págs. 154/157 e, no Brasil, Pellegrini Grinover, As garantias constitucionais cit., principalmente págs. 99/100. 
É aqui que poderia surgir o contraste entre as garantias do "devido processo legal"(18), iquestionavelmente forjadas para acudir a um processo tradicional, de caráter individualista ${ }^{(19)}$, e o instrumental idôneo para a solução dos novos conflitos, a serem resolvidos em um enfoque social.

4 - Inicialmente, porém, deve ser ressaltado que, no campo mesmo das garantias do "devido processo legal", é possível detectar uma notável transformação, decorrente da transposição do enfoque, do individual para o social $^{(20)}$.

Com efeito, se de um lado as posições de vantagem das partes no processo podem ser vistas como direitos públicos subjetivos, segundo a óptica de tipo individualista que privilegia o interesse pessoal sobre o social; do outro lado podem ser vistas como garantias, e não apenas das partes mas também do justo processo, segundo a óptica de tipo publicista que dá relevância ao interesse geral na justiça da decisão( ${ }^{(21)}$.

Garantias das partes e do próprio processo: eis o enfoque completo e harmonioso do conteúdo da cláusula do devido processo legal, que não se limite ao perfil subjetivo da ação e da defesa ${ }^{(22)}$ como direitos, mas que acentue, também e especialmente, seu perfil objetivo.

(18) V. supra nota 16. Sobre a cláusula do "due process of law", suas origens e desenvolvimento, nos sistemas da "common law" e da "civil law", pedimos vênia para remeter mais uma vez o leitor ao nosso "As garantias", cit.

(19) Clássica é a afirmação de Goldschmidt, no sentido de que o direito processual não poderia senão florescer no terreno do liberalismo: Der Prozess als Rechtslage, 1925, Prefácio.

(20) Com relação à genérica mudança de enfoque do fenômeno processual, do individual para o social, v. Barbosa Moreira, Tendências contemporâneas cit., págs. 6/11. Como veremos, a"mudança se deve à própria transformação da sociedade (infra, $n$ ㅇ 5).

(21) Sobre essa dúplice perspectiva, na análise de problemas conexos com o exercício da defesa, v. Denti, "La difesa come diritito e come garanzia" e Grevi, "Rifiuto del difensore e inviolabilità della difesa", in Il problema dell'autodifesa nel processo penale, Bologna, Zanichelli, 1977, respectivamente p. 48 e ss. e p. 9 e ss. Com relação à idéia de garantias processuais, vistas concomitantemente como sendo das partes e da jurisdição, remetemos o leitor ao nosso artigo "O princípio da ampla defesa", in Rev. PGE, São Paulo, n 19, 1981/1982, p. 9 e ss.

(22) Utilizamos a expressão em sentido lato, não somente para abranger o poder de iniciativa e o direito às exceçōes, mas para compreender todas as posições de vantagem - direitos, poderes, faculdades, ônus - que as partes podem desenvolver ao longo do iter processual. 
Garantias e não direitos, porquanto são de índole assecuratória, e não meramente declaratória, visando a tutelar o exercício de outros direitos e guardando com estes relação de instrumentalidade ${ }^{(23)}$.

Garantias, não apenas das partes, mas sobretudo da jurisdição: porque se, de um lado, é interesse dos litigantes a efetiva e plena possibilidade de sustentarem suas razōes, de produzirem suas provas, de influírem concretamente sobre a formação do convencimento do juiz, do outro lado essa efetiva e plena possibilidade constitui a própria garantia da regularidade do processo, da imparcialidade do juiz, da justiça das decisōes.

Nesse enfoque, parece claro que a visão de um processo abstratamente garantidor das partes é insuficiente e inadequado para satisfazer as exigências atuais de respeito aos valores constitucionais ${ }^{(23 a)}$. Tanto assim que se chega a falar, na Itália, em velho e novo "garantismo"(23b). O primeiro, de natureza formal, preso ao modelo individualista do século passado; o segundo, de natureza substancial, aceitando as implicaçōes derivadas não só da nova relação entre o juiz e as partes ${ }^{(23 c)}$, como da própria transformaçāo das controvérsias.

(23) Sobre os diversos sentidos do termo garantia, em contraposição a direitos, culminando com a acepção supra, já traçada por Ruy Barbosa (República: Teoria e Prática (textos selecionados e coordenados por Hilton Rocha), Vozes, Câmara dos Deputados, 1978, pág. 24), ver Ferreira Filho, Grinover e Cunha Ferraz, Liberdades públicas, São Paulo, 1978, pág. 119 e ss. Ver também a recente explanação sobre direitos e garantias, em suas várias acepções e no sentido empregado no texto, de José Afonso da Silva, Curso de Direito constitucional positivo, 2 ed., São Paulo, 1984, págs. $293 / 5$ e 548/554. Sobre a ação e a defesa, como garantias, cujo conteúdo é o direito ao processo justo, ver Cintra, Grinover e Dinamarco, Teoria geral do processo cit., págs. 50/51 e 239/240.

(23a) Cf. Denti, Valori costituzionali e cultura processuale, Riv. dir. proc., 1984, p. 456.

(23b) Assim, por exemplo, Denti, Il ruolo del giudice nel processo civile tra vecchio e nuovo garantismo, in Riv. trim. dir. proc. civ., 1984, p. 726 e ss.

(23c) Denti, Valori cost. cit., p. 462. Sobre a transformação do "juiz árbitro" em "juiz garantidor", v. novamente Denti, Il ruolo cit., pág. 728/9. 
5 - É que, passando a examinar os conflitos emergentes, percebe-se que eles também defluem da transformação da sociedade, de individualista que era, em sociedade de massa ${ }^{(24)}$. E se é verdde que tais conflitos são próprios da civilização pós-industrial, desenvolvida sobretudo em países de economia avançada $^{(25)}$, não se pode desconhecer a especial importância de que sua solução se reveste nos países em desenvolvimento, por significar não apenas a institucionalização de novas formas de participação na administração da justiça e de gestão racional dos interesses públicos e privados ${ }^{(26)}$, mas por assumir também relevante papel promocional de conscientização política ${ }^{(27)}$. É como se a exigência de solução dos novos conflitos tivesse duas almas: uma, adequada às sociedades mais avançadas; outra, mais necessária ainda aos países em desenvolvimento.

E esta exigência de soluçāo dos novos conflitos enquadra-se exatamente no renovado ideário constitucional do processo, pelo qual a via jurisdicional há de transformar-se na concreta garantia dos direitos e interesses substanciais assegurados pela Constituição.

(24) Cappelletti, Formazioni sociali e interessi di gruppo davanti alla giustizia civile, Riv. dir. proc., 1975 , p. 365 , fala em "violaçōes de massa" próprias de "uma sociedade, ou civilização, de produção de massa, de trocas e consumo de massa; e também certamente de conflitos ou conflituosidade de massa"

(25) Segundo Denti (I procedimenti non giudiziali di conciliazione come istituzioni alternative, in Riv. dir. proc., 1980, págs. 410/437) o fenômeno seria próprio dos países "de capitalismo avançado" ou "maduro", enquanto Cappelletti observa que não é ele típico ou exclusivo dos modernos países ocidentais, preferindo falar em "sociedades de economia avançada": Appunti su conciliatore e conciliazione, in Riv. trim. dir. proc. civ. 1981, págs. 53 e 64.

(26) Para os interesses difusos, v. Denti, Le azioni a tutela di interessi collettivi, Riv. dir. proc., 1974, págs. 539/540; Vigoriti, Interessi collettivi e processo: la legittimazione ad agire, Milão, Giuffrè, 1979, p. 3/16; Pellegrini Grinover, A problemática dos interesses difusos, in "A tutela dos interesses difusos" cit., p. 32. Sobre as atividades de mediação das forças sociais, na conciliação e nos juizados de pequenas causas, $v$. Denti e Vigoriti, Le rôle de la conciliation comme moyen d'éviter le procès et de résoudre le conflit, Relação geral do VII Congresso Internacional de Direito Processual, Würzburg, 1982, p. 368 e ss.; Pellegrini Grinover, Conciliação e Juizado de Pequenas Causas, in Juizado especial cit., págs. 159/160.

(27) Ver, de nossa autoria, "Ações coletivas para a tutela do ambiente e dos consumidores: a lei no 7347, de 24/7/1985", in AJURIS, n 36, março de 1986, pág. 7 e ss., também publicada na Itália, na Riv. dir. proc., 1986, no Uruguay (Revista Uruguaya de Derecho Procesal, no 2, 1986) e na Argentina (Jus, La Plata, no 38, 1986). Com relação à "justiça menor", v. Watanabe, Assistência judiciária e juizados de Pequenas Causas, in Juizado especial cit., p. 161 e ss. 
De modo que parece claro que o contraste entre as garantias do "devido processo legal" e um processo adequado à diversa realidade social somente se coloca num enfoque insuficiente, se não superado, das garantias constitucionais do processo. Mas não existem fraturas entre a necessária reformulação dos institutos processuais e o "neo-garantismo"(28a), exatamente na medida em que este afasta as concepçōes meramente formais para preocupar-se com as exigências substanciais de acesso à justiça, de igualdadế real, de paridade das armas, de concreta e efetiva possibilidade de todos obterem a tutela jurisdicional.

\section{II - OS INTERESSES DIFUSOS NO QUADRO DAS GARANTIAS CONSTITUCIONAIS DO PROCESSO}

6 - Mas é sobre os denominados interesses difusos ${ }^{(29)}$ que nosso estudo se deterá agora, para a análise das garantias constitucionais do processo destinado à sua tutela.

Para tanto, parecem convenientes algumas observaçōes prévias, importantes por seus reflexos sobre o tema.

Os interesses difusos vêm sendo conceitualmente apartados de outros interesses coletivos, em razão da inexistência de um vínculo jurídico que ligue os seus titulares ${ }^{(30)}$. Embora se trate sempre de interesses meta-individuais, a doutrina reserva a denominação "coletivos" para os comuns a categorias de pessoas, unidas entre si por uma relação-base: a sociedade comercial, o condomínio, a família, os entes profissionais, o próprio sindicato. E esse vínculo jurídico, ou relação-base, permite a identificação dos componentes do grupo.

Ao contrário, entendem-se por interesses difusos aqueles que, não se fundando em um vínculo jurídico, repousam sobre dados de fato freqüentemente

(28) A expressão é de Denti, Il ruolo cit., p. 729.

(29) Ver supra, nota 13.

(30) Entre tantos, v. Barbosa Moreira, "A ação popular do direito brasileiro como instrumento de tutela jurisdicional dos chamados "interesses difusos", in Temas de Direito Processual, São Paulo, Saraiva, 1977, p. 110 segs. e Pellegrini Grinover, A problemática dos interesses difusos, in "A tutela dos interesses difusos cit., p. 29 segs. $\mathrm{Na}$ Itália, a distinção fora feita por Recchia, Considerazioni sulla tutela degli interessi diffusi nella Costituzione, in "La tutela degli interessi diffusi nel diritto comparato", Milão, Giuffrè, 1976, págs. 38-39 e por De Vita, La tutela degli interessi collettivì nella prospettiva del sistema francese, ibid, págs. 350/351. 
genéricos e contingentes, acidentais e mutáveis: morar na mesma região, consumir o mesmo produto, viver sob determinadas circunstâncias sócio-econômicas, submeter-se a particulares empreendimentos. Seús titulares são, portanto, uma pluralidade de pessoas, em número indeterminado e indeterminável.

7 - Do ponto de vista objetivo, deve ser entendida em termos a afirmação de que se trataria sempre de um bem indivisível, no sentido de que a satisfação de um dos titulares importaria necessariamente na satisfação de todo o grupo, ao mesmo tempo em que a lesão de um deles significaria contemporaneamente ofensa a todos os membros da coletividade. Isso é verdade com relação ao bem coletivamente considerado (ambiente, saúde, informação correta), mas a ofensa a este bem pode ocasionar, ao mesmo tempo, lesão aos diversos bens de que são individualmente titulares os componentes do grupo ${ }^{(31)}$.

Daí porque, quando se trata da reparação, esta pode ser estabelecida com relação ao bem indivisivelmente considerado (reconstituição do meio ambiente, por ex.), sem prejuízo, porém, da indenização pessoal devida aos diferentes sujeitos. E isso é inevitável, quando se considere que os interesses difusos não são interesses públicos no sentido tradicional da palavra, mas antes interesses privados, de dimensão coletiva ${ }^{(32)}$.

Aliás, essa distinção dá margem a dois tipos diversos de açōes coletivas para a tutela dos interesses difusos: no sistema da "common law", por ex., as "class actions" podem também ser utilizadas para a reparação de danos individualmente sofridos ${ }^{(33)}$, enquanto no sistema da "civil law" até agora se permaneceu no âmbito da condenação à obrigação de fazer ou não fazer, ou à reparação do dano em sua dimensão coletiva ${ }^{(34)}$.

(31) Barbosa Moreira fala, para o primeiro caso, de "interesses essencialmente coletivos" e, para o segundo, de "interesses acidentalmente coletivos" (A proteçāo jurídica dos interesses coletivos, in "Temas de Direito Processual, Terceira Série, Saraiva, São Paulo, 1984, págs. 195/196).

(32) Cappelletti, Formazioni sociali cit., págs. 368/9; Vigoriti, Interessi collettivi e processo - La legittimazioni ad agire, Giuffrè, Milão, 1979, p. 21 ss.

(33) Após a distribuição da indenização entre os membros da "class", o sistema norteamericano prevê a "fluid recovery", uma espécie de resíduo não reclamado, cuja aplicação pode ser destinada a finalidades diversas, conquanto conexas ao interesse em jogo: v. Cappelletti, Formazioni sociali cit., págs. 395/6.

(34) É o caso, por exemplo, da lei brasileira no 7347, de 24 de julho de 1985, que destina a indenização a um fundo, que a utilizará para a reconstituição dos bens lesados. 
Como se pode facilmente intuir, diversos são os problemas e as possíveis soluções processuais, quando se trate de açōes coletivas para a tutela do bem coletivamente considerado, ou para a satisfação dos diversos membros da coletividade, pessoalmente atingidos.

8 - Num e noutro caso, todavia, colocam-se questões ligadas aos limites subjetivos da coisa julgada e, conseqüentemente, ao contraditório e ao direito de defesa ${ }^{(35)}$. Questões típicas das garantias processuais das partes e da jurisdição, suscitando problemas de natureza constitucional.

Recorde-se o famoso caso Eisen, julgado pela Corte Suprema dos Estados Unidos da América, em 1974: tratava-se de uma demanda em que 3,5 milhōes de operadores da Bolsa de Nova Iorque acionaram, por intermédio do Sr. Eisen, agentes que haviam lesado cerca de 6 milhöes de pessoas, impondo-lhes uma sobretaxa ilegal. O Tribunal não determinara a citação individual de todos os agentes, mas sim a de 7 mil deles, escolhidos por amostragem, o que representaria um gasto de US\$20.000, a ser suportado pela classe Ré. Mas a Suprema Corte, invocando as garantias constitucionais, considerou necessária a citação individual, que custaria à classe Autora US\$225.000. Esta desistiủ do processo, o que representou, sem dúvida, um rude golpe para as "class actions"(36).

Mas a verdade é que a solução constitucional para a problemática das ações ideológicas há de ser buscada numa óptica social e coletiva, capaz de amoldar as garantias clássicas à configuração típica dos conflitos de massa: numa dimensão que será necessariamente diversa, mas que não significará o seu abandono.

(35) Sobre a interação entre defesa e contraditório, em que de um lado a defesa - correlata à ação - é abrangente garantia do justo processo, sendo o contradit6rio sua emanação; mas, de outro lado, é pelo contraditório que a defesa se manifesta e é garantida, ver, da Autora, Defesa, contraditório, igualdade e "par condicio" na óptica do processo de estrutura cooperatória, in "O processo constitucional em Marcha", organizado por Pellegrini Grinover, São Paulo, Max Limonad, 1985, Introdução, p. 11.

(36) Cappelletti, Formazioni, cit., págs. 397/398; Vigoriti, Interessi cit., págs. 278/280. No volume de Vigoriti vem reproduzida na íntegra a decisão da Corte Suprema sobre o caso Eisen (págs. 291/306). 
9 - De primordial importância, na análise das garantias constitucionais do processo nas ações coletivas, é o regime da coisa julgada. $E$ isso porque, de um lado, a própria configuração das ações ideológicas exige, pelo menos até certo ponto, a extensão da coisa julgada "ultra partes"(37); e, de outro lado, a limitação da coisa julgada às partes é princípio inerente ao contraditório e à defesa, na medida em que o terceiro, juridicamente prejudicado, deve poder opor-se à sentença proferida "inter alios", exatamente porque não lhe foi dado participar da relação jurídico-processual ${ }^{(38)}$.

Mas, no regime da coisa julgada, é preciso distinguir. Em primeiro lugar, diverso é o tratamento com relação aos interesses denominados "coletivos" e aos interesses "difusos" propriamente ditos ${ }^{(39)}$. Nos primeiros, a autoridade da sentença fica necessariamente restrita aos componentes do grupo, perfeitamente identificáveis; e o portador dos interesses, legitimado à ação, age naturalmente dentro de limites mais circunscritos. É mais fácil, então, utilizar certas técnicas tradicionais, pelas quais os co-titulares são representados ou processualmente

(37) Referimo-nos aqui, à extensão "ultra partes" da própria coisa julgada, como qualidade da sentença e de seus efeitos (a imutabilidade); não à eficácia natural da sentença que atua "ergá cmnes", mas à qual o terceiro juridicamente prejudicado pode opor-se: é a distinção magistralmente traçada por Liebman (Efficacia e autorità della sentenza, Milão, 1935, republicada em 1962) e acolhida de modo praticamente unânime pela doutrina brasileira (Pellegrini Grinover, Notas à $2^{\text {a }}$ edição brasileira da Eficácia e autoridade da sentença de Liebman, Rio de Janeiro, Forense, 1981; ver também, da Autora, Eficácia e autoridade da sentença penal, São Paulo, Ed. Revista dos Tribunais, 1978). Com relação à extensão da coisa julgada "ultra partes", nas ações em defesa dos interesses difusos, v., por todos, Cappelletti, Formazioni sociali cit., págs. 394/401; Denti, Le azioni a tutela di interessi collettivi, in Riv. dir. proc., 1974, págs. 546/549 e Aspetti processuali della tutela dell'ambiente, in "La responsabilità dell'impresa per i danni all'ambiente e ai consumatori”. Giuffrè, Milão, 1978, p. 66.

(38) V., recentemente, reportando-se à lição de Liebman, Pellegrini Grinover, Eficácia e autoridade cit., p. 61 e Monteleone, I limiti soggettivi del giudicato civile, Pádua, Cedam, 1978, p. 162. Por último, no mesmo sentido, embora adotando linha diversa, Luiso, Principio del contradittorio ed efficacia della sentenza verso i terzi, Milão, Giuffrè, 1981, págs. 3 e 7.

(39) V. supra, no 6 . 
substituídos pela pessoa ou ente legitimado à ação( ${ }^{(40)}$, havendo ordenamentos que possibilitam a exclusão do processo de quem não deseje submeter-se à coisa julgada ${ }^{(41)}$.

Já quando se trata de interesses difusos propriamente ditos, diversa é a dimensão do problema, na medida em que a impossibilidade prática de se determinarem os titulares dos interesses torna mais aguda a necessidade de extensão da coisa julgada "erga omnes". Mas aqui o vem a pelo a na segunda distinção(42).

10 - É que a pretensão de tutela dos interesses difusos pode ter natureza diversa, visando à sentença meramente declaratória, constitutiva ou condenatória. Esta, por sua vez, pode consistir em condenação à obrigação de fazer ou não fazer, ou no pagamento de indenização.

Tratando-se de sentença meramente declaratória ou constitutiva ${ }^{(43)}$ ou

(40) É a têcnica utilizada, nos sistemas de "civil law", para a declaração de nulidade das assembléias societárias, ou para responsabilizar diretores pelos atos nocivos ao patrimônio social; no condomínio, para que qualquer condônimo aja contra outro, em mora nas contribuiçōes; na famúlia, para a tutela dos interesses comuns, como na anulação do casamento e na interdição. Situações semelhantes ocorrem quando o sindicato é legitimado à ação coletiva trabalhista ou, para certas associações profissionais, quanto à legitimação para a defesa dos interesses dos associados. Trata-se, às vezes, de legitimação ordinária e outras, de extraordinária: Barbosa Moreira, A ação popular cit., págs. 111/112.

(41) É a técnica das "class actions", ao menos para certas controvérsias: Federal Rules of Civil Procedure de 1966, Rule 23, "c", 2 e "c", 3 (Ver, sobre o assunto, Vigoriti, Interessi collettivi cit., págs. 282/283). No Brasil a solução foi proposta pelo Projeto de lei n 3987/84, de autoria do Deputado Pratini de Moraes, não transformado em lei.

(42) V. supra, no 7.

(43) Como exemplo, lembre-se a ação popular constitucional brasileira, que visa à anulação ou à declaração da nulidade dos atos da administração, com legitimação ativa do cidadão no gozo dos direitos políticos (art. 153 \& 31 Const. e lei no 4717, de 26 de junho de 1965). A ação vem sendo utilizada com freqüência para a tutela de interesses difusos ligados ao meio ambiente e a bens de valor artístico, estético, histórico e turístico: v. Barbosa Moreira, A ação popular cit.; Pellegrini Grinover, A tutela jurisdicional dos interesses difusos no sistema brasileiro, in "Tutela dos interesses difusos" cit., p. 180 e ss. (o estudo, inicialmente redigido em italiano, foi publicado pela riv. trim. dir. proc. civ. de 1984: na versão italiana, v. p. 68 e ss.). 
ainda de sentença que condene à obrigação de fazer ou não fazer ${ }^{(44)}$, a solução utilizada é, via de regra, a da coisa julgada "erga omnes"(45), temperada por vezes pelo princípio da extensão "secundum eventum litis"(46). Não se desconhecem os argumentos que se levantam contra a coisa julgada "secundum eventum litis", quando a fórmula seja utilizada apenas para os casos de acolhimento da demanda, nas açōes que versem sobre bens indivisíveis ${ }^{(47)}$. Melhor parece a solução do direito brasileiro: a autoridade da coisa julgada vale "erga omnes", quer em caso de acolhimento, quer no de rejeição do pedido, pelo mérito. Mas, se improcedente a demanda por insuficiência de provas, simples-

(44) Mencionem-se os exemplos da "Gesetz gegen den unlanteren Wettbewerb" da Alemanha federal (lei 21 de julho de 1965) contra atos de concorrência desleal; da "Loi Royer" francesa (lei 27 de dezembro de 1973) de proteção dos consumidores; da recente lei brasileira no 7347 , de 24 de julho de 1985 , em defesa do ambiente (em sentido lato) e do consumidor (supra, nota 27).

(45) Ver supra, nota 37, principalmente parte final.

(46) A necessária reestruturaçāo dos esquemas processuais, indispensável à tutela jurisdicional dos interesses difusos, também exige a revisão das posições clássicas contrárias à coisa julgada "secundum eventum litis": (v., entre tantos, Chiovenda, Principi di diritto processuale civile, Jovene, Nápoles, 1923, p. 924; E. Betti, Diritto processuale civile italiano, 2ª edição, Foro it., roma, 1936, p. 603 e p. 619, nota 58; Redenti, Il giudizio civile con pluralità di parti, Milão, Giuffrè, ed. de 1960, p. 12 (nota 10) e p. 58 (nota 47). Aliás, já Allorio observava que o princípio não merecia as críticas que lhe eram movidas, embora reconhecesse que as exceções à proibição deveriam resultar da lei (La cosa giudicata rispetto ai terzi, Giuffrè, Milão, 1935, p. 272). Mais recentemente, G. Puglliese preconiza que a extensão do julgado "secundum eventum litis" seja tomado em séria consideração (Giudicato civile (dir. vigente), in. Enc. dir., vol XVIII, Giuffrè, Milão, 1969, p. 889). Assim também Carpi (L'efficacia “ultra partes" della sentença civile, Milão, Giuffrè, 1974, p. 347 ss. com nota 128).

(47) Denti afirma que a solução do julgado "secundum eventum litis" sria consentânea com as técnicas do ordenamento italiano, mas inadequada a esse tipo de ação ("Aspetti processuali cit., p. 66). No mesmo sentido Luiso, Principio del contradittorio cit., p. 210 , nota 319 . Vigoriti observa que a não oponibilidade a terceiros da coisa julgada negativa não só frustra a necessidade de uniformidade da cognição a respeito do interesse coletivo, mas ainda impõe ônus excessivo ao réu, obrigado a repetir sua defesa, sem poder opor a eficácia de um julgado favorável (Interessi collettivi cit., p. 112). Contra a fórmula da coisa julgada "erga omnes", só "in utilibus", v. no Brasil, entre todos, Barbosa Moreira. A ação popular cit., p. 122/123, apontando a falha denunciada por Schwab, e que pode levar a coisas julgadas contraditorias (a primeira, negativa para um co-legitimado; a segunda, se procedente a ação, com eficácia "erga omnes", abrangendo também o primeiro, que perdeu a demanda). 
mente não haverá coisa julgada, podendo a ação ser renovada, ainda que com idêntico fundamento, desde que baseada em novas provas ${ }^{(48)}$.

Com relação à ação que tenda a uma sentença condenatória à indenização, cremos que a mesma solução pode ser adotada tranqüilamente quando se trate da reparação pelo dano indivisível ${ }^{(49)}$.

11 - Mas maiores cautelas deverão ser tomadas em ações coletivas que visem à reparação pelos danos pessoalmente sofridos ${ }^{(50)}$. Aqui, o julgado negativo, que se opusesse a quem não foi parte na causa, viria ferir mais fundo as situaçōes jurídicas substanciais que o direito tutela ${ }^{(51)}$. Ademais, os inconvenientes da coisa julgada "ultra partes", só quando favorável o julgado ${ }^{(52)}$, seriam reduzidas, porquanto a legitimação à ação coletiva poderia ser deferida apenas a entes públicos e associaçōes representativas, ficando aberta a possibilidade de ações posteriores, em caso de derrota, apenas às pessoas físicas, em caráter individual. E, de qualquer modo, a se deixar as coisas como estão, a coisa julgada ficaria da mesma forma limitada às partes, não eliminando a possibilidade de inúmeras demandas sucessivas contra o mesmo réu.

$\mathrm{Na}$ reconhecida impossibilidade de assegurar a efetiva informação e a

(48) É a inteligente solução da lei da ação popular, apoiada pela doutrina mais recente (Barbosa Moreira, A ação popular cit., p. 123; Pellegrini Grinover, A tutela jurisdicional cit., p. 181) e agora adotada pela lei 7347, de 24 de julho de 1985 (supra, nota 27, primeira parte). O XI Congresso Argentino de Direito Processual (La Plata, 1981) aprovou sugestão que substancialmente adota a do legislador brasileiro: Rev. Col. Abog. de La Plata, no 41, p. 197, conclusão no 5.

(49) Para a distinção, v. supra, no 7. A técnica é expressamente acolhida também para a ação condenatória à reparação do dano coletivo pela lei brasileira 7347, de 24 de julho de 1985 , referida na nota supra.

(50) Supra, no 7. A solução processual da "civil law", para este tipo de ação, poderia ser o da condenação genérica, limitada à fixação da responsabilidade pelos prejuízos ocasionados, com as sucessivas ações individuais para a prova do dano e de seu montante.

(51) Aliás, era esta a hipótese do caso Eisen (supra, $\mathrm{n}^{\circ}$ 8), cujo precedente, segundo Vigoriti, não se estende a ações que não tenham caráter indenizatório (Interessi collettivi cit., p. 279 , nota 47 ).

(52) Supra, nota 47. 
oportunidade de intervenção aos diversos titulares de direitos e interesses ${ }^{(53)}$, o certo é que cada vez mais se acentua a tendência para a extensão da coisa julgada somente para favorecer os terceiros, como se verifica pela recente lei da Alemanha Federal sobre as cláusulas gerais dos $\operatorname{contratos}^{(53 a)}$.

E recentemente a doutrina italiana tem sustentado que os casos expressos de coisa julgada "secundum eventum litis" não representam exceções taxativas, mas sim a expressão de um princípio geral aplicável em casos análogos ${ }^{(53 b)}$.

12 - Seja como for, nas ações coletivas há uma profunda correlação entre o reg̣ime da coisa julgada e a legitimação para a causa. E até mesmo a constitucionalidade do julgado "ultra partes" depende dos esquemas de legitimação.

A análise do problema mostra, entre as soluções possíveis, as seguintes: 1) legitimação concorrente a qualquer dos co-titulares, que pode agir em juízo, na tutela do interesse comum, isoladamente ou em litisconsórcio; 2) legitimação de alguns portadores dos interesses difusos, como as formações sociais, cujos objetivos institucionais coincidam com os interesses a serem tutelados; 3) legitimação de órgãos estatais, dentre eles o Ministério Público ${ }^{(54)}$.

É certo que todas essas alternativas, isoladamente consideradas, apresentam vantagens e desvantagens, de modo que freqüentemente se esboçam soluçōes compostas, articuladas e flexíveis capazes de levar à adequada tutela dos interesses difusos, pela combinação de critérios diversos ${ }^{(55)}$. Mas a verdade é que cada vez mais se empreendem esforços no sentido de buscar, no portador dos interesses comuns legitimado à ação, garantias de seriedade e eficiência,

(53) Sobre o problema da informação, nas "class actions", v. Vigoriti, op. cit., p. 277 segs.

(53a) V. De Nova, La legge tedesca sulle condizioni generali di contratto, in Riv. dir. civ., 1978 , I, p. 107 ss.

(53b) V. Carpi, op. cit., p. 348; Costantino, Brevi note sulla tutela giurisdizionale degli interessi collettivi davanti al giudice civile, in Le azioni a tutela di interessi collettivi, Pádua, Cedam, 1976, p. 235; Denti, Valori costituzionali cit., p. 457/459.

(54) Proto Pisani, Appunti preliminari per uno studio sulla tutela giurisdizionale degli interessi collettivi (o più esattamente: superindividuali) innanzi al giudice civile, in "Le azioni a tutela di interessi collettivi”, Cedam, Pádua, 1976, p. 274. Vigoriti, embora partindo de critério diverso, chega praticamente ao mesmo esquema (Interessi collettivi cit., p. 105 e ss.).

(55) Cappelletti, Formazioni sociali cit., p. 383. 
para que a "representação" do conjunto de interessados se faça de maneira "adequada"(56). E é justamente na óptica da "representatividade adequada" que podem ser resolvidos os problemas constitucionais da informação e dos limites subjetivos da coisa julgada, nas ações coletivas.

13 - Com efeito, a cláusula da "representatividade adequada" tem fundamento constitucional e pretende exatamente conciliar as garantias do devido processo legal com as ações coletivas, cujas decisōes sejam vinculativas para toda a categoria ${ }^{(57)}$.

Por ela, a parte ideológica leva a juízo o interesse meta-individual, "representando" concretamente o grupo titular do interesse, que terá exercido seus direitos processuais, através das garantias da defesa e do contraditório asseguradas ao "representante"(58). O mecanismo baseia-se na concepção de que o esquema representativo é apto a garantir aos membros da categoria a melhor defesa judicial, a ponto de afirmar-se que nesse caso o julgado não atuaria propriamente "ultra partes", nem significaria real exceção ao princípio dos limites subjetivos da coisa julgada, mas configuraria antes um novo conceito de "representação substancial e processual", adaptado às novas exigências emergentes na sociedade ${ }^{(59)}$.

É certo que na "common law" a existência da "adequacy of representation" "é analisada caso por caso pelo juiz, que poderá verificar se houve a "fair notice" do processo e se a defesa dos interesses da categoria foi desenvolvida com os necessários cuidados. mas, como já se notou ${ }^{(60)}$, os ordenamentos da

(56) A fórmula "representatividade adequada" é de origem norte-americana (Federal Rules of Civil Procedure de 1966, Rule no 23 "a". com a exigência de que "the representative parties will fairly and adquatily protect the interest of the class"). Não é preciso dizer que o termo "representação" não tem aqui o sentido técnico-jurídico que lhe atribui o sistema da "civil law".

(57) V. Vigoriti, Interessi collettivi cit., p. 271 e ss.

(58) Cappelletti, Formazioni sociali cit., p. 399.

(59) Assim Monteleone, I limiti soggettivi cit., págs. 177/178.

(60) V. Capri, L'efficacia " "ultra partes" della sentenza civile, Milão, Giuffrè, 1974, p. 123 e ss. No mesmo sentido, Taruffo, I limiti soggettivi del giudicato e le "class actions", Riv. dir. proc., 1969, págs. 635/636. 
"civil law", ainda que com técnicas diversas, poderiam extrair do sistema norte-americano elementos úteis à solução do problema. $\mathrm{E}$ a idéia já vem acolhida em via legislativa ${ }^{(61)}$.

14 - $\mathrm{O}$ que vale frisar é que, assim como repugna às garantias constitucionais a sujeição "ex post" ao julgado de terceiros que permaneceram estranhos ao juízo ${ }^{(62)}$, coaduna-se com elas a idéia de "representatividade adequada" dos interesses da categoria por parte de pessoas e sobretudo de entidades exponenciais $^{(63)}$.

E hoje, a orientação dominante é francamente no sentido de que não há incompatibilidade entre o "devido processo legal" e as técnicas das ações coletivas para a tutela dos interesses difusos ${ }^{(64)}$. Reconhece-se até mesmo coincidência e complementariedade entre o interesse individual e o social ${ }^{(65)}$. E, a nosso ver, também entre o processo constitucional e as modernas exigências de efetiva tutela jurisdicional dos interesses emergentes na sociedade de massa ${ }^{(66)}$.

(61) V., por exemplo, a Lei Royer francesa (supra, nota 44) que, nos arts. 45 e 46 - combinados com o decreto de 17 de maio de 1974 - fixa certos requsitos para garantir a representatividade das associações legitimadas às ações para a defesa do consumidor (v. De Vita, La tutela giurisdizionale cit., págs. 382/383). Também no Brasil, a recente lei 7347, de 24 de julho de 1985 (supra, nota 27), exige das associações requisitos que nada mais indicam do que a busca da representatividade (art. 5\%). Mais longe ia o Projeto 3034/1984, (de autoria de Cândido Dinamarco, Kazuo Watanabe, Waldemar Mariz de Oliveira Jr. e da autora destas linhas) e do qual se originou a nova lei: combinando critérios próprios da "civil law" e da "common law", confiávamos ao juiz o exame da adequação e da capacidade das associações, sendo a constituição prévia e os objetivos institucionais simples dados a serem tomados na devida consideração: ver da autora "Ações coletivas cit."

(62) Cf. Monteleone, I limiti soggettivi cit, p. 168.

(63) Sobre a importância das formações sociais e dos corpos intermediários para a defesa dos interesses difusos, ao lado de sua relevância para o modelo participativo, v. Cappelletti, Formazioni sociali cit., p. 398 e ss.; Pellegrini Grinover, A problemática cit., págs. $32 / 33$.

(64) Cf. Vigoriti, Interessi collettivi cit., p. 272, com jurisprudência norte-americana in nota 31 .

(65) Monteleone, I limiti soggettivi cit., págs. 176/177.

(66) Supra, no 1 e no 2 . 
15 - Claro que tudo depende, em última análise, de rigorosos controles sobre a "representatividade adequada", instituídos pela lei; e ainda, quando se trate de ações para a tutela de interesses difusos divisíveis ${ }^{(67)}$, da efetiva informação e da possibilidade de intervenção asseguradas concretamente aos interessados ou até mesmo da extensão da coisa julgada "ultra partes", só para favorecer indivíduos pessoalmente lesados ${ }^{(68)}$. Sem jamais perder de vista, portanto, $\mathrm{o}$ justo ponto de equilíbrio entre as novas exigências de tutela e o direito de defesa ${ }^{(69)}$.

Trata-se, pois, de examinar as clássicas garantias constitucionais à luz dos novos conflitos e de reestruturá-las, numa dimensão social ${ }^{(70)}$. De dar-lhes aplicação numa amplitude ainda maior. De lutar por sua permanência e seu vigor, ajustando-as aos interesses de massa. Para que o processo, com suas garantias constitucionais, possa servir de instrumento à efetiva realização dos direitos, assim como eles se apresentam na sociedade contemporânea.

(67) Supra, no 7.

(68) Supra, no 11.

(69) Proto Pisani, Appunti preliminari cit., p. 815; Taruffo, I limiti soggettivi cit., p. 617.

(70) Cappelletti fala em "garantismo social ou coletivo", em substituição ao "garantismo processual de marca individualista": Formazioni sociali cit., págs. 398/399. 